\title{
DIGITAL MARKETING UNTUK PEMBERDAYAAN MASYARAKAT BINAAN YAYASAN SOKOGURU UNGARAN
}

\author{
Ragil Saputra, Eko Adi Sarwoko, Dinar Mutiara KN, Rismiyati, Edy Suharto
}

Departemen Ilmu Komputer/Informatika Fakultas Sains dan Matematika Universitas Diponegoro ragil.saputra@live.undip.ac.id.

\begin{abstract}
The Sokoguru Foundation is a non-governmental organization (NGO), with one of its activities to empower the communities. After interviewing with the foundation managers and a survey of the community member, the results show that the ability to do entrepreneurship online is essential for the community. Therefore, the community services team provides training for the community about social media use, especially using Instagram to do digital marketing. This community service activity methodology uses a Participatory Rural Approach in the form of training and mentoring. The service is carried out in 3 stages: preparation, training, and evaluation. Preparation is done by seeking information on material requirements for training. The training stage is carried out using an online system with Zoom Meeting (due to COVID-19 19 pandemic). Next, the training is filled with a presentation from the community service's team, question and answer, and sharing experiences. This service activity's evaluation results add new knowledge for participants (100\%), usefulness (52.6\%: beneficial, 47.4\%: useful). As well as increasing interest in online marketing by $73.7 \%$, from the previous 57\%. Apart from scientific articles, this activity's output is in the form of training modules, articles on the Kompas mass media, and video documentation on the YouTube channel.
\end{abstract}

Keywords: empowering the communities, digital marketing, social media, Instagram.

\begin{abstract}
Abstrak
Yayasan Sokoguru merupakan Lembaga Swadaya Masyarakat (LSM) dengan salah satu kegiatannya adalah sebagai tempat pemberdayaan masyarakat. Berdasarkan hasil wawancara dengen pengelola yayasan dan survey terhadap masyarakat binaan, diperlukan kemampuan untuk berwirausaha secara online. Oleh karena itu pada kegiatan pengabdian masyarakat ini, tim pengabdian memberikan pelatihan pemanfaatan sosial media khususnya Instagram untuk melakukan digital marketing.

Metodologi kegiatan pengabdian ini menggunakan Partisipatori Rural Approach berupa pelatihan dan pendampingan. Pengabdian dilaksanakan melalui 3 tahapan: persiapan, pelatihan dan evaluasi. Persiapan dilakukan dengan menggali informasi kebutuhan materi untuk pelatihan. Tahap pelatihan, dikarenakan pada suasana pandemi dilakukan dengan sistem daring dengan Zoom Meeting. Pelatihan diisi dengan penyampaian materi, tanya jawab dan sharing pengalaman.

Hasi evaluasi, kegiatan pengabdian ini menambah pengetahuan baru bagi peserta (100\%), kebermanfaatan (52,6\% : sangat bermanfaat, 47,4\% : bermanfaat). Serta meningkatkan minat untuk melakukan pemasaran online sebesar $73,7 \%$ dari sebelumnya $57 \%$. Output kegiatan ini selain artikel ilmiah, juga berupa modul pelatihan, artikel pada media masa kompasiana, dan dokumentasi video di channel youtube.
\end{abstract}

Kata kunci: pemberdayaan masyarakat, digital marketing, sosial media, Instagram 


\section{PENDAHULUAN}

Berdasarkan data dari We Are Social pada tahun 2019 terdapat 150 juta pengguna media sosial di Indonesia, dan sebanyak 56\% jumlah populasi. Dan pengguna aktif mencapai 130 juta jiwa. Jenis media sosial yang paling sering digunakan adalah Youtube sebesar 88\%, disusul oleh Whatsapp, Facebook dan Instagram (We Are Social, 2019). Oleh karena itu cukup penting untuk meningkatkan kualitas sumber daya manusia melalui pelatihan pemasaran digital menggunakan sosial media.

Menurut Van Dijk ( 2013), media sosial merupakan suatu platform media yang memfokuskan pada keberadaan pengguna yang memberikan fasilitas dalam beraktifitas ataupun bekerjasama. Oleh sebab itu, media sosial bisa dilihat bagaikan medium atau sarana online yang memantapkan ikatan antar pengguna sekaligus sebagai suatu jalinan sosial (Nasrullah, 2015). Sedangkan bagi Hanson sosial media merupakan media yang didesain agar memudahkan interaksi sosial yang bersifat interaktif 2 arah. Sosial media yang bertumpu pada teknologi internet telah merubah pola penyebaran informasi atau data yang tadinya bersifat satu ke banyak audien menjadi dari banyak ke banyak audiens (Purnama, 2011)

Ide dasar digital marketing bermula dari hadirnya internet, yang kemudian di kembangkan situs mesin pencari. Ketika itu, perkembangan penggunaan internet mendunia pada tahun 2001, pasar dikuasai oleh Google Inc dan Yahoo! Inc. Tren pencarian informasi melalui situs internet berkembang pada pertengahan tahun 2006 dan satu tahun berikutnya, penggunaan perangkat bergerak meningkat signifikan. Sehingga secara langsung menyebabkan peningkatan jumlah pengguna internet. Pada saat itu masyarakat dari seluruh dunia mulai terhubung atau berinteraksi melalui media sosial (Khan, et al, 2013).

Istilah digital marketing atau pemasaran digital menurut American Marketing Association (AMA) adalah suatu aktivitas oleh individu maupun institusi, yang menjalankan kegiatan yang difasilitasi oleh teknologi digital dalam membuat, berbagi, dan menyampaikan informasi berharga kepada audien dan pihak yang berkepentingan lainnya (Kannan, 2017). Tujuan pemasaran digital dapat meningkatkan visibilitas kunjungan ke website, dan dapat membangun merek sendiri dengan kehadiran media sosial. Otomatisasi pemasaran dapat menghemat waktu dan memberikan interaksi yang lebih personal (Lara, 2020).

Usaha untuk meningkatkan ketrampilan dan peningkatan mutu sumber daya manusia di Kabupaten Semarang sudah banyak dilakukan, antara lain Yayasan Sokoguru Ungaran. Yayasan ini merupakan Lembaga Swadaya Masyarakat (LSM) yang terletak di wilayah Kabupaten Semarang dengan fokus kegiatan di pemberdayaan masyarakat. Yayasan Sokoguru juga bergerak bidang kesehatan, pendidikan dan lingkungan (Sokoguru, 2018).

Pemberdayaan masyarakat pada kegiatan ini difokuskan pada pelaku usaha UMKM atau calon pelaku usaha yang masih merintis bisnis. Media sosial merupakan potensi yang besar untuk pemberdayaan pelaku UMKM dalam rangka aktivitas pemasaran produknya (Stelzner, 2015).

Media sosial diartikan sebagai aplikasi yang menggunakan internet yang membuat dasar teknologi Web 2.0 yang memberi peluang diciptakannya 
dan disebarluaskan konten digital pengguna atau user generated content /UGC (Scheepers, et, al, 2012). Beberapa kelebihan digital marketing antara lain: target bisa diatur sesuai, hasil cepat terlihat, biaya jauh lebih murah, jangkauan lebih luas, dapat diakses kapanpun tidak terbatas waktu (Wardhana, 2015).

Oleh karena itu pada kegiatan pengabdian masyarakat, tim pengabdian Departemen Ilmu Komputer / Informatika Fakultas Sains dan Matematika Universitas Diponegoro bekerja sama dengan Yayasan Soko Guru untuk memberikan pelatihan digital marketing kepada masyarakat binaan yayasan tersebut.

Sebelum melakukan kegiatan pengabdian, tim melakukan survey untuk mengetahui kondisi mitra yang berkaitan dengan wirausaha ataupun internet marketing. Sebesar 52\% masyarakat binaan sudah memiliki usaha skala UMKM. Sisanya sebanyak $48 \%$ belum memiliki usaha maupun aktivitas perdagangan. Sebanyak 57\% sudah menggunakan marketplace maupun sosial media untuk menjual atau membeli barang. Alasan masyarakat mengapa tidak menggunakan internet untuk melakukan internet marketing dikarenakan belum paham bagaimana cara menggunakannya (43\%), hasilnya tidak jelas (42\%) dan terlalu merepotkan sebesar (14\%). Disisi lain, semua masyarakat binaan sudah menggunakan sosial media dalam kesehariaanya, dengan prosentase terbesar Whatsapp, disusul Instagram, Facebook, Twitter, TikTok, dan lain-lain.

Kegiatan pengabdian ini dilakukan dengan maksud untuk meningkatkan pemahaman kepada masyarakat binaan Yayasan Sokoguru terutama sebagai sarana untuk memasarkan produk secara digital.

\section{METODE}

Metodologi kegiatan pengabdian ini menggunakan partisipatori rural approach berupa pelatihan dan pendampingan. Secara umum dilaksanakan melalui 3 tahapan: persiapan, pelatihan dan evaluasi.

\section{Tahapan Persiapan}

Tahapan persiapan dilakukan dengan melakukan wawancara kepada pengurus Yayasan Sokoguru. Pelatihan jenis apa saja yang pernah dilaksanakan, kebutuhan materi pelatihan yang diminati oleh masyarakat binaan yayasan. Selain dengan wawancara, persiapan juga dilakukan dengan survei melalui penyebaran kuesioner.

\section{Tahapan Pelatihan}

Pelatihan digital marketing masyarakat binaan Yayasan Sokoguru Ungaran dilaksanakan secara online melalui webinar yang telah dilaksanakan pada 17 Oktober 2020.

Materi yang disampaikan antara lain sebagai berikut:

1. Pengenalan tren digital marketing.

2. Pemberian contoh pemanfaatan mesin pencari dalam pemasaran produk, teknologi informasi terkini dalam pengembangan web, seperti search engine, chatbot, VR/AR (ugmented Reality), AI (Artifial Inteligence), dll.

3. Pengenalan konsep-konsep promosi dan pemasaran dengan memanfaatkan social media Instagram.

4. Tip trik posting Instagram, membuat konten menarik, posting pada waktu yang tepat, pemanfaatan Instagram Ads /iklan, dan influencer atau selebgram untuk membantu promosi produk. 
5. Sharing pengalaman permasalahan yang muncul ketika berbisnis dengan memanfaatkan sosial media.

\section{Evaluasi}

Tahapan Monitoring dan

Setelah selesai kegiatan pelatihan, monitoring dan evaluasi dilakukan dengan melakukan survei kepuasan terhadap pelatihan. Survei ini mencakup pendapat peserta pelatihan tentang kebermanfaatan dari program pelatihan, kesesuaian materi, durasi waktu, serta tindak lanjut setelah mengikuti pelatihan ini.

\section{HASIL DAN PEMBAHASAN}

\section{Sesi Pembukaan}

Kegiatan ini dipandu oleh Rismiyati, B.Eng, M.Cs sebagai pembawa acara dengan mengantarkan keseluruhan rangkaian kegiatan dari mulai pembukaan sampai selesai. Perkenalan Yayasan Sokoguru disampaikan oleh Pembina Yayasan, Taufik Kurniawan, S.Si, M.Kom. Yayasan ini berawal dari sebuah gerakan kepedulian masyarakat terhadap bahaya penyakit HIV Aids dalam bentuk Lembaga Swadaya Masyarakat (LSM), kemudian berkembang menjadi sebuah yayasan yang bergerak dibidang pemberdayaan. Yayasan Sokoguru terbuka kepada siapa saja instansi apapun untuk bermitra.

Sebagai perwakilan tim pengabdian Drs. Eko Adi Sarwoko, menyampaikan bahwa tim sebagai akademisi memahami konsep, teori tentang bidang ilmu internet dan aplikasinya, namun tidak mempunyai tempat praktek. Sehingga kerjasama ini sangat bermanfaat, karena disisi lain yayasan mempunyai masyarakat binaan yang membutuhkan. Sehingga kerjasama ini sangat penting, dan diharapkan membawa dampak yang besar bagi kedua insitusi. Sesi pembukaan disajikan pada gambar 1 .

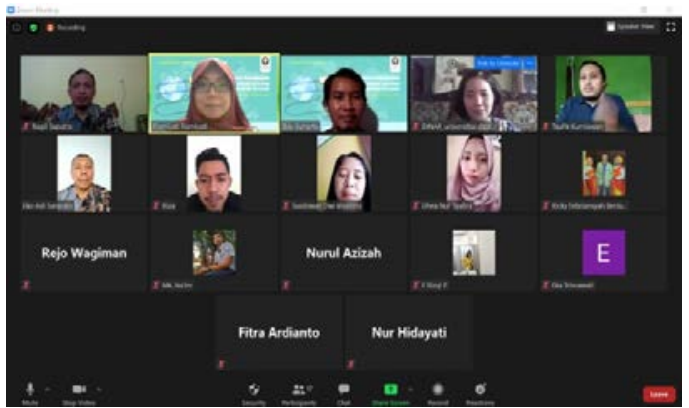

Gambar 1. Acara Pembukaan

\section{Sesi Pelatihan}

Pelatihan daring dipandu oleh Edy Suharto, S.T, M.Kom sebagai moderator, dengan dua pemateri yaitu Ragil Saputra, S.Si, M.Cs dan Dinar Mutiara KN, S.T, M.Info (Tech), Ph.D. Materi di mulai dengan paparan tren internet marketing, yang berisi teknologi informasi terkini yang sudah hadir di internet. Seperti fitur search engine google, tren social media marketing, dan teknologi pengembangan web sebagai contohnya gamification, VR/AR (Virtual / Augmented Reality), AI (Artificial Inteligence), dll. Salah satu tampilan materi pertama di sajikan pada gambar 2.

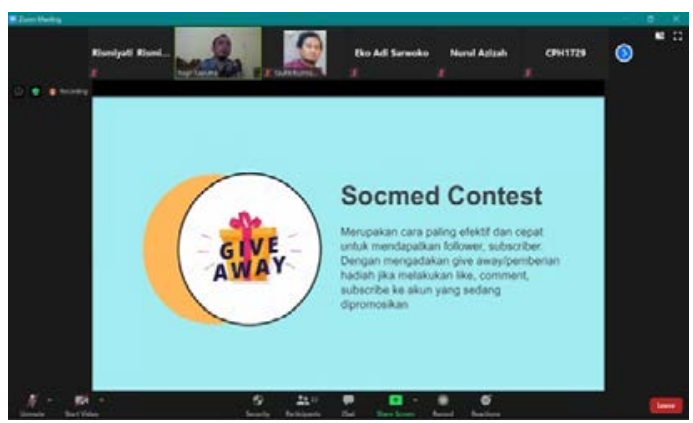

Gambar 2. Paparan Materi 1

Materi yang kedua secara lebih spefisik pemanfaatan social media Instagram, karena banyak digunakan oleh masyarakat binaan. Strategi 
pemasaran pada Instagram menjadi topik utama, diawali dengan penjelaskan bagaimana melakukan setting Instagram bisnis, jenis-jenis postingan IG, cara melakukan posting, membuat konten menarik, kapan waktu yang tepat dalam posting, memanfaatkan Instagram Ads, dan kerjasama dengan influencer atau selebgram untuk meningkatkan jangkauan pemasaran. Penyajian materi kedua di sajikan pada gambar 3.

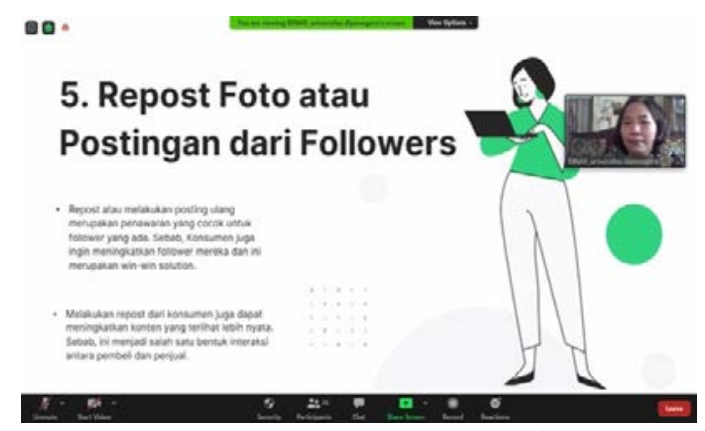

Gambar 3. Paparan Materi 2

\section{Sesi Tanya Jawab}

Diakhir acara peserta pelatihan diberi kesempatan untuk tanya jawab, maupun sharing pengalaman. Beberapa pertanyaan pada sesi diskusi antara lain disajikan pada Tabel 1. Peserta sangat antuias sekali dengan banyaknya pertanyaan dari peserta, dan memberikan kesan pesan yang positif.

Tabel 1. Transkrip Pertanyaan

\begin{tabular}{ll}
\hline No & \multicolumn{1}{c}{ Pertanyaan } \\
\hline 1. & $\begin{array}{l}\text { Apakah orang awam seperti saya bisa } \\
\text { buat web sendiri? Aplikasi apa yg bisa } \\
\text { saya pakai dan apa aja yang perlu saya } \\
\text { siapkan? }\end{array}$ \\
2. & $\begin{array}{l}\text { Untuk Bapak Ragil, strategi apa yang } \\
\text { paling tepat disaat pandemi dan kondisi } \\
\text { ekonomi sedang tidak baik, bagi pelaku }\end{array}$ \\
bisnis online pemula? & $\begin{array}{l}\text { Pak/Bu. bagaimana agar olshop kita } \\
\text { (instagram) tampak meyakinkan. }\end{array}$ \\
apakah perlu kita membeli follower \\
Dengan adanya program ini, saya \\
mempunyai semangat baru, tp \\
sayangnya di tempat saya akses
\end{tabular}

internet kurang begitu mendukung, untuk bisa eksis jualan melaui aplikasi instagram gimana bu Dinar?

5. Pak Ragil, saya mau bertanya, Apakah ada riset jalur marketing apa yang paling banyak mendatangkan pembeli.

6. Assalamu alaikum...

Bapak/ibu saya mau bertanya, mohon arahan bagaimana cara/ strategi agar kita ada di urutan pertama pencarian google? Terimakasih

7. Ijin bertanya. Cara memasarkan brand low budget selain pasang iklan di marketplace?

8. Berkaitan dengan penargetan (pembuatan pemirsa) dan tujuan di FB Ads dan IG Ads. Kira-kira untuk saat ini yg paling efektif dalam menarik interaksi yg mana ya pak? Apakah harus ada riset dulu? Terimakasih

\section{Berdasarkan tabel 1, terlihat bahwa sebagian peserta sudah melakukan pemasaran secara online melalui social media. Dan mereka menginginkan agar cara atau metode penjualan menjadi lebih efektif. Misalnya bagaimana agar tampilan IG menjadi menarik sekaligus meyakinkan, bagaimana mengenalkan merk atau brand dengan budget minimal, strategi riset apa yang perlu dilakukan untuk mendatangkan banyak pembeli.}

Disisi lain, peserta juga masih ada yang baru berminat untuk melakukan internet marketing. Telihat dari pertanyaan-pertanyaan seputar bagaimana persiapan memulai bagi orang awam, menggunakan aplikasi apa saja.

Kemudian tim pemateri memberikan tanggapan atas pertanyaan peserta, dan juga diberikan contoh bagaimana melakukannya. Misalnya pertanyaan bagaimana melakukan riset marketing. Pemateri menjelaskan dari mulai hal yang sederhana misalnya menggunakan google trend. Dimana kita bisa mencari tren pencarian barang berdasarkan kata kunci di mesin pencari 
google. Sebagai contoh menggunakan kata kunci “jas hujan” (seperti pada gambar 4), karena menjelang musim penghujan pasti akan ada kenaikan pencarian jas hujan dibulan oktober. Ini berarti jika mau melakukan penjualan produk perlengkapan musim hujan, misal payung, jas hujan akan mengalami peningkatan. Strategi atau cara yang lebih lengkap sudah disediakan di platform social media. Misalnya Facebook analytics maupun Instagram analytics, namun ini tersedia untuk pengguna yang sudah mencapai target follower tertentu, untuk Instagram minimal 10.000 follower.

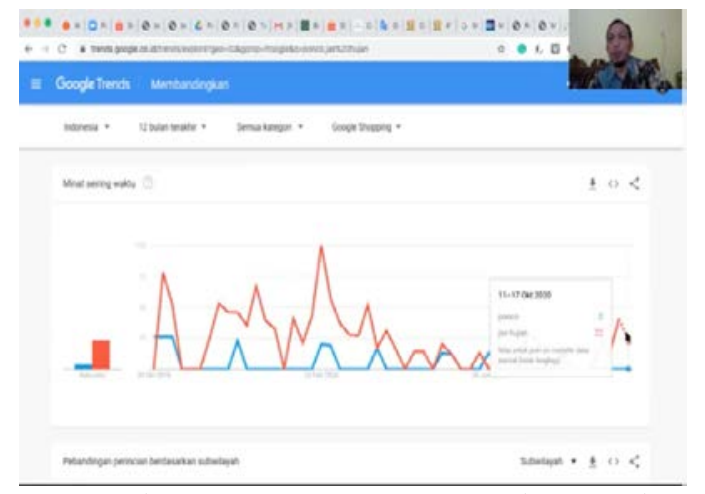

Gambar 4. Penggunaan Google Trend

\section{Monitoring dan Evaluasi}

Tahapan akhir kegiatan pengabdian masyarakat ini adalah tahapan evaluasi. Selain dilakukan secara internal, evaluasi juga dilakukan dengan cara kuesioner pasca pelatihan. Ada beberapa pertanyaan yang diajukan kepada peserta melalui kuesioner secara off line untuk mendapatkan feed back dari peserta kegiatan, antara lain:

1. Pertanyaan pertama yang diajukan kepada responden adalah setelah mendapatkan pelatihan apakah peserta mendapatkan pengetahuan yang baru? Sebanyak 100\% responden menyatakan mendapatkan pengetahuan baru.

2. Apakah materi memenuhi harapan atau tidak. Sebanyak 21,1\% respon dari peserta menyatakan kegiatan ini sangat sesuai harapan, sedangkan $78,9 \%$ responden menyatakan sesuai dengan harapan.

3. Seberapa manfaat kegiatan ini dirasakan oleh peserta? Dengan menggunakan skala linked (1-5), hasilnya sebanyak 52,6\% responden menyatakan sangat bermanfaat, $47,4 \%$ peserta menyatakan bermanfaat.

4. Apakah waktu pelatihan sudah sesuai atau belum? Berdasarkan kuesioner sebanyak $84,2 \%$ menyatakan waktu sudah sesuai, sedangkan $15,8 \%$ lainnya menyatakan waktunya terlalu singkat.

5. Bagaimana minat untuk melakukan pemasaran online setelah mengikuti pelatihan? Hasilnya sebanyak 73,7\% sangat berminat untuk melakukan pemasaran online menggunakan social media, dan sisanya sebanyak 26,3\% masih mempertimbangkan.

\section{Analisis Hasil Kegiatan}

Sesuai dengan hasil kegiatan dan evaluasi tersebut, pelaksanaan pelatihan Digital Marketing untuk Pemberdayaan Masyarakat Binaan Yayasan Sokoguru telah selesai dilaksanakan. Analisa pengabdian ini dilihat dari beberapa aspek yaitu:

\section{Pemilihan lokasi pengabdian}

Dalam pemilihan lokasi, yayasan yang rutin melakukan beberapa kegiatan pemberdayaan masyarakat merupakan tempat yang tepat unutk mendapatkan materi tersebut. Hal ini dikarenakan masyarakat binaan terdiri dari berbagai latar belakang profesi pekerjaan, sehingga kurang mempunyai pengalaman dan pengetahuan tentang pemasaran di dunia internet. Selain itu, perbedaan latar belakang pendidikan juga yang mengakibatkan sebagian masyarakat binaan belum mampu 
memanfaatkan secara optimal internet untuk menunjang kegiatan pemasaran.

\section{Pemilihan topik.}

Topik digital marketing melalui sosial media ini dipilih dengan mempertimbangkan seluruh masyarakat binaan yayasan sudah menggunakan sosial media, tidak hanya pada masyarakat binaan yang tinggal di perkotaan, tetapi juga pada masyarakat pedesaan.

\section{Target pelatihan}

Target pelatihan telah sesuai, karena masyarakat binaan telah mendapatkan pengetahuan baru mengenai pemasaran melalui internet. Diharapkan ke depannya, masyarakat binaan tersebut mampu menyebarkan ilmu dan wawasannya kepada masyarakat binaan yang lain di wilayah masing-masing.

\section{Waktu dan Materi pelatihan}

Sesuai dengan hasil evaluasi, waktu pelatihan yang diberikan cukup dapat membantu mendapatkan pengetahuan dasar tentang tend teknologi informasi terkini, serta penggunaan social media Instagram untuk internet marketing. Sesuai dengan hasil evaluasi, materi yang disampaikan juga telah memenuhi harapan peserta.

Beberapa kendala yang ditemukan dalam pengabdian yaitu, pelatihan secara daring sehingga interaksi dengan peserta kurang maksimal. Serta praktek langsung penggunaan social media Instagram juga tidak bisa di evaluasi secara langsung, bagaimana peserta melakukan aktvitas posting dan lain sebagainya.

\section{SIMPULAN}

\footnotetext{
Berdasarkan hasil pembahasan, maka dapat ditarik beberapa kesimpulan. Secara umum masyarakat binaan atau sahabat sokoguru belum banyak yang melakukan pemasaran
}

melalui internet. Selain itu, wawasan pengetahuan tentang penggunaan social media untuk melakukan internet marketing masih minim. Sehingga kegiatan berupa pelatihan digital marketing sangat diperlukan.

Hasil kegiatan ini memberikan pengetahuan baru (100\%), memberikan manfaat bagi peserta $(52,6 \%$ : sangat bermanfaat, dan 47,4\% : bermanfaat). Hasil setelah pelatihan, strategi dan cara menggunakan sosial media untuk melakukan pemasaran online sudah dipahami dan berhasil dipraktekan sehingga meningkatkan minat untuk melakukan pemasaran online sebesar $73,7 \%$.

\section{UCAPAN TERIMA KASIH}

Kegiatan ini didanai dengan dana Selain APBN Fakultas Sains dan Matematika UNDIP tahun 2020.

\section{DAFTAR PUSTAKA}

Kannan, P. K. and Hongshuang, L. 2017. Digital Marketing: A Framework, Review and Research Agenda. International Journal of Research in Marketing, vol. 34, no. 1, pp. 22-45, 2017.

Khan, F and Siddiqui. 2013. The Importance of Digital Marketing: An Exploratory Study to Find The Perception and Effectiveness of Digital Marketing amongst The Marketing Proffesionals in Pakistan, Journal of Information Sytems and Operations Management, pp. 1-8.

Lara, C. 2020. Top Digital Marketing Trends for 2020 and 2021, 14 October 2020. [Online]. Available: 
https://www.theedigital.com/bl og/digital-marketing-trends.

Nasrullah, R. 2015. Media Sosial: Prosedur, Tren, dan Etika. Bandung: Simbiosa Rekatama Media.

Purnama, H. 2011. Media Sosial di Era Pemasaran 3.0 Corporate and Marketing Communication. Jakarta Pusat Studi Komunikasidan Bisnis. Program Pasca Sarjana Universitas Mercu Buana. pp $107-124$.

Sokoguru. 2018. Profil Lembaga Yayasan Sokoguru. Ungaran

Stelzner, M. A. 2015. How Marketers Are Using Social Media to GrowTheir Businesses, [Online]. Available: http://www.socialmediaexamin er.com/report2015/

Stockdale, R., Ahmed, A. and H. Scheepers. 2012. Identifying
Business Value From The Use Of Social Media: An Sme Perspective. Pacific Asia Conference on Information Systems. Hochiminh City. Vietnam

Wardhana, A. 2015. Strategi Digital Marketing dan Implikasinya pada Keunggulan Bersaing UKM di Indonesia. Seminar Keuangan dan Bisnis IV. Bandung.

We Are Social. 2019. Digital 2019: Global Internet Use Accelerates - We Are Social. [Online]. Available: https://wearesocial.com/ blog/2019/01/digital-2019global-internet-use-accelerates. 